\title{
Development of PVC and PP Resin Pellet Certified Reference Materials for Heavy Metal Analysis with Respect to the RoHS Directive
}

\author{
Masaki OHATA ${ }^{\dagger}$ and Akiharu HioKI \\ Inorganic Standard Section, Inorganic Analytical Chemistry Division, National Metrology Institute of Japan \\ (NMIJ), National Institute of Advanced Industrial Science and Technology (AIST), Tsukuba Central 3-9, \\ 1-1-1 Umezono, Tsukuba, Ibaraki 305-8563, Japan
}

\begin{abstract}
The PVC (polyvinyl chloride) and the PP (polypropylene) resin pellet certified reference materials (CRMs, NMIJ CRM 8123-a and 8133-a) with respect to the RoHS (restriction of the use of hazardous substances in electrical and electronics equipment) directive were developed in the present study. Both the sample pretreatment and the measurement procedures for the determination of $\mathrm{Cd}, \mathrm{Cr}, \mathrm{Hg}$ and $\mathrm{Pb}$ in the $\mathrm{PVC}$ and the PP resin pellets were examined, and several analytical methods were developed. Microwave acid digestion and dry-ashing followed by acid digestion procedures were examined as sample pretreatment procedures. In the case of measurement procedures, an inductively coupled plasma mass spectrometry (ICPMS) including an isotope dilution mass spectrometry (IDMS) and an ICP optical emission spectrometry (ICPOES) were used. Since the analytical results obtained by different analytical methods showed good agreement within their uncertainties estimated, it was concluded that the analytical methods established in this study were reliable with high accuracy. The homogeneity and the stability of $\mathrm{Cd}, \mathrm{Cr}, \mathrm{Hg}$ and $\mathrm{Pb}$ in these plastic CRMs were also evaluated, and the results revealed sufficient homogeneity of $0.3-0.7 \%$ and stability for more than 5 years. From these results, it is considered that these CRMs are useful CRM for the determination of $\mathrm{Cd}, \mathrm{Cr}, \mathrm{Hg}$ and $\mathrm{Pb}$ in plastics with respect to the RoHS directive.
\end{abstract}

(Received November 21, 2012; Accepted December 22, 2012; Published February 10, 2013)

\section{Introduction}

The EU (European Union) legislated the RoHS (restriction of the use of hazardous substances in electrical and electronics equipment) directive, which became effective in July, 2006., According to the directive, the concentration values of hazardous substances, such as $\mathrm{Cd}, \mathrm{Cr}(\mathrm{VI}), \mathrm{Hg}, \mathrm{Pb}, \mathrm{PBB}$ (poly-brominated biphenyl) and PBDE (poly-brominated diphenyl ether), in electrical and electronics equipment produced in the EU, as well as transported from other areas, should be restricted. Plastic materials are well known to be widespread used in electrical and electronics equipment. It is also well recognized that the hazardous substances mentioned above have been added into plastics to improve the noncombustible character as well as the coloring. In addition, new plastics without hazardous substances are considered to be adulterated with used plastics during the recycling process. Consequently, standard analytical procedures and certified reference materials (CRMs) of hazardous substances in plastics are of great interest, and demanded to check the concentration values of these hazardous substances in electrical and electronics equipment regulated in the RoHS directive. ${ }^{3-17}$

Several plastic CRMs with respect to the RoHS directive have been developed so far for both chemical analysis, $3,4,6,11,14$ and

† To whom correspondence should be addressed.

E-mail: m-oohata@aist.go.jp direct analysis $8,10,12,13,15-17$ that request the sample pretreatment procedure to dissolve plastics, and can measure hazardous substances directly using such techniques as X-ray fluorescence spectrometry (XRF), respectively. In the case of CRM development, reliable analytical methods with high accuracy that comprise the sample pretreatment and the measurement procedures are required. Generally, plastic is dissolved by an acids digestion procedure, and the solution obtained is measured by such measurement procedures as atomic absorption spectrometry (AAS), inductively coupled plasma optical emission spectrometry (ICPOES) and inductively coupled plasma mass spectrometry (ICPMS). The most crucial point is the sample pretreatment procedure, which has an effect on an accurate determination, because the loss and the contamination of hazardous substances are of concern if it is not appropriate and is not appropriately conducted. Both the open and the close systems used for the sample pretreatment procedure are well known, and are still applied for element analysis such as hazardous substances regulated in the RoHS directive combined with the measurement procedures mentioned above. From this point of view, both the sample pretreatment and the measurement procedures are worthwhile to examine for the development of CRM as well as the establishment of standard analytical procedures.

In this study, the PVC (polyvinyl chloride) and the PP (polypropylene) resin pellet CRMs for the determination of $\mathrm{Cd}, \mathrm{Cr}$, $\mathrm{Hg}$ and $\mathrm{Pb}$ with respect to the RoHS directive were developed. Both the sample pretreatment and the measurement procedures 
were examined, and several analytical methods were developed. Microwave acid digestion and dry-ashing followed by acid digestion procedures were examined as sample pretreatment procedures. In the case of measurement procedures, an ICPMS including an isotope dilution mass spectrometry (IDMS) and an ICPOES were used. The analytical results obtained for different analytical methods as well as the results concerning the homogeneity and the stability of elements were discussed in this study.

\section{Experimental}

\section{Instrumentation}

The instruments used were Agilent 7500cs ICPMS (Agilent, Tokyo, Japan) and Optima 4300DV ICPOES (PerkinElmer, USA). The typical operating conditions of these analytical instruments are described in Ref. 14. For the sample pretreatment procedures, a microwave digestion system (Ethos 1, Milestone, Italy) and an electric furnace (Fujiwara Seisakusyo, Ibaraki, Japan) for the dry-ashing procedure were used. A heating program of the microwave digestion system, described in Ref. 14, was used with a minor amendment (a maximum temperature of $230^{\circ} \mathrm{C}$ was programmed in this study). Cleaning of the polytetrafluoroethylene (PTFE) vessel for the microwave digestion system was performed using $8 \mathrm{~mL}$ of $70 \% \mathrm{HNO}_{3}$ by the same microwave heating. The PTFE vessel was rinsed more than three times by Milli-Q purified water (Milli-Q Element, Millipore, Tokyo, Japan) after microwave heating, and the dry one was used for microwave digestion. The operating condition of the electric furnace for the dry-ashing procedure is described in the Results and Discussion section. The quartz beaker used was cleaned by soaking in $c a .1 \mathrm{M} \mathrm{HNO}_{3}$ bath for more than two days and dried prior to the dry-ashing procedure.

\section{Reagents}

The reagents of $\mathrm{CdO}(99.5 \%,<1 \mu \mathrm{m}$, Sigma-Aldrich Co. LLC, USA), HgS (99\%, Wako Pure Chemical Industries, Ltd., Japan), $\mathrm{PbCrO}_{4}$ (>90\%, Wako Pure Chemical Industries, Ltd., Japan), and Cr-acetylacetonate (97\%, Acros Organics, Belgium) were used to prepare candidate CRMs of the PVC and the PP resin pellets. The acids used for sample digestion were $60 \%$ and $70 \% \mathrm{HNO}_{3}$ (EL grade, Kanto Chemical Co. Inc., Japan), 95\% $\mathrm{H}_{2} \mathrm{SO}_{4}$ (reagent grade, Wako Pure Chemical Industries, Ltd., Japan), $30 \% \mathrm{H}_{2} \mathrm{O}_{2}$ (reagent grade, Wako Pure Chemical Industries, Ltd., Japan), and $36 \% \mathrm{HCl}$ (EL grade, Kanto Chemical Co. Inc., Japan). The standard solutions (ca. $1000 \mathrm{mg}$ $\mathrm{kg}^{-1}$ ) of $\mathrm{Cd}, \mathrm{Cr}, \mathrm{Hg}$ and $\mathrm{Pb}$ used were primary standard solutions prepared at National Metrology Institute of Japan (NMIJ, Tsukuba, Ibaraki, Japan). The standard solutions were well characterized, and their standard uncertainty was $0.05 \%(k=1)$. Enriched spike solutions for IDMS were prepared from enriched isotope materials of ${ }^{111} \mathrm{Cd}$ enriched metal (plate form), ${ }^{53} \mathrm{Cr}$ enriched metal (powder form), ${ }^{201} \mathrm{Hg}$ enriched oxide ( $\mathrm{HgO}$, powder form) and ${ }^{206} \mathrm{~Pb}$ enriched carbonate $\left(\mathrm{PbCO}_{3}\right.$, powder form), which were purchased from Oak Ridge National Laboratory (Oak Ridge, TN), by dissolving with appropriate concentrations of acids. A mixed spike solution was prepared from each enriched spike solution, and the concentrations of enriched isotopes of elements were determined accurately by reverse IDMS. In this study, we adopted the values of the isotopic abundances for $\mathrm{Cd}, \mathrm{Cr}$ and $\mathrm{Hg}$ listed in IUPAC, ${ }^{18}$ because these values could be accepted generally. On the other hand, a $\mathrm{Pb}$ isotoic standard solution prepared from NIST SRM 981 (metal wire form) was used to determine the $\mathrm{Pb}$ isotopic
Table 1 Examined acids and their performances on microwave acid digestion procedure (Ethos 1, Milestone) with respect to $c a$. $0.1 \mathrm{~g}$ of the PVC and the PP resin pellet CRMs

\begin{tabular}{ccc}
\hline & \multicolumn{2}{c}{ Performance } \\
\cline { 2 - 3 } Acids (amount) & PVC & PP \\
\hline $95 \% \mathrm{H}_{2} \mathrm{SO}_{4}(4 \mathrm{~mL})$ & $\times$ & $\times$ \\
$95 \% \mathrm{H}_{2} \mathrm{SO}_{4}(4 \mathrm{~mL})+70 \% \mathrm{HNO}_{3}(4 \mathrm{~mL})$ & $\odot$ & $\odot$ \\
$95 \% \mathrm{H}_{2} \mathrm{SO}_{4}(4 \mathrm{~mL})+60 \% \mathrm{HNO}_{3}(4 \mathrm{~mL})$ & $\odot$ & $\odot$ \\
$60 \% \mathrm{HNO}_{3}(2 \mathrm{~mL})+36 \% \mathrm{HCl}(6 \mathrm{~mL})$ & $\triangle$ & $\bigcirc$ \\
$60 \% \mathrm{HNO}_{3}(6 \mathrm{~mL})+36 \% \mathrm{HCl}(2 \mathrm{~mL})$ & $\triangle$ & $\odot$ \\
$70 \% \mathrm{HNO}_{3}(8 \mathrm{~mL})$ & $\bigcirc$ & $\odot$ \\
$70 \% \mathrm{HNO}_{3}(8 \mathrm{~mL})$ & $\triangle$ & $\odot$ \\
\hline
\end{tabular}

(): Complete digestion can be achieved by a single microwave heating procedure.

$\bigcirc$ : Complete digestion can be achieved by a single microwave heating procedure with reduced number of vessels (from 10 to 5).

$\triangle$ : Complete digestion can be achieved if the microwave heating procedure is repeated for two or three times (number of vessels is 10). $\times$ : Complete digestion can not be achieved by a single microwave heating procedure (black solution with high viscosity is obtained).

abundance for both the $\mathrm{Pb}$ primary standard solution and the $\mathrm{Pb}$ in the plastic pellets, because different $\mathrm{Pb}$ isotopic abundances were observed obviously between the IUPAC value and the $\mathrm{Pb}$ standard solution as well as the $\mathrm{Pb}$ in the plastic pellets. Milli-Q purified water was used to prepare acids with appropriate concentrations which were used to prepare mixed standard solutions as well as the sample solutions for measurements.

\section{Samples}

In order to prepare candidate $\mathrm{PVC}$ and $\mathrm{PP}$ resin pellet CRMs that contain ca. $100 \mathrm{mg} \mathrm{kg}^{-1}$ of $\mathrm{Cd}$ and $c a .1000 \mathrm{mg} \mathrm{kg}^{-1}$ of $\mathrm{Cr}$, $\mathrm{Hg}$ and $\mathrm{Pb}$, certain amounts of reagents of $\mathrm{CdO}, \mathrm{HgS}, \mathrm{PbCrO}_{4}$ and $\mathrm{Cr}$-acetylacetonate were mixed by dry blend with base resin pellets of PVC or PP in a plastic bag. The mixed materials were extruded by an extruder at $200^{\circ} \mathrm{C}$; then, the extruded plastics were pelletized by a pelletizer and homogenized. The preparation procedure from extrusion to homogenization was carried out for a total of three times to achieve sufficient homogeneity of elements in the candidate PVC and PP resin pellet CRMs. The preparation procedures mentioned above were similar to that of our previous work. ${ }^{14}$ The final PVC and PP resin pellets obtained were $c a .30 \mathrm{mg}$ and $c a .10 \mathrm{mg}$ for each one pellet, respectively. The measured densities of the PVC and the PP resin pellets were $1.280 \pm 0.026 \mathrm{~g} \mathrm{~cm}^{-3} \quad(k=2)$ and $0.8990 \pm 0.0103 \mathrm{~g} \mathrm{~cm}^{-3}(k=2)$, respectively. Before weighing these pellets, they were dried at $80^{\circ} \mathrm{C}$ for $1 \mathrm{~h}$ in an electric oven and cooled in a desiccator with silica gel for $1 \mathrm{~h}$ to remove any moisture. ${ }^{14}$

\section{Results and Discussion}

\section{Examination of the microwave acid digestion procedure}

The acid combinations were examined to achieve complete digestion of the PVC and the PP resin pellets by the microwave digestion procedure. Table 1 lists the examined acid combinations as well as their performances using the microwave digestion system with respect to $c a .0 .1 \mathrm{~g}$ for both the PVC and the PP resin pellets. The mixed acid of $\mathrm{HNO}_{3}$ and $\mathrm{H}_{2} \mathrm{SO}_{4}$ achieved complete digestion for both plastic pellets in a single microwave heating program; however, a few amounts of $\mathrm{Pb}$ 

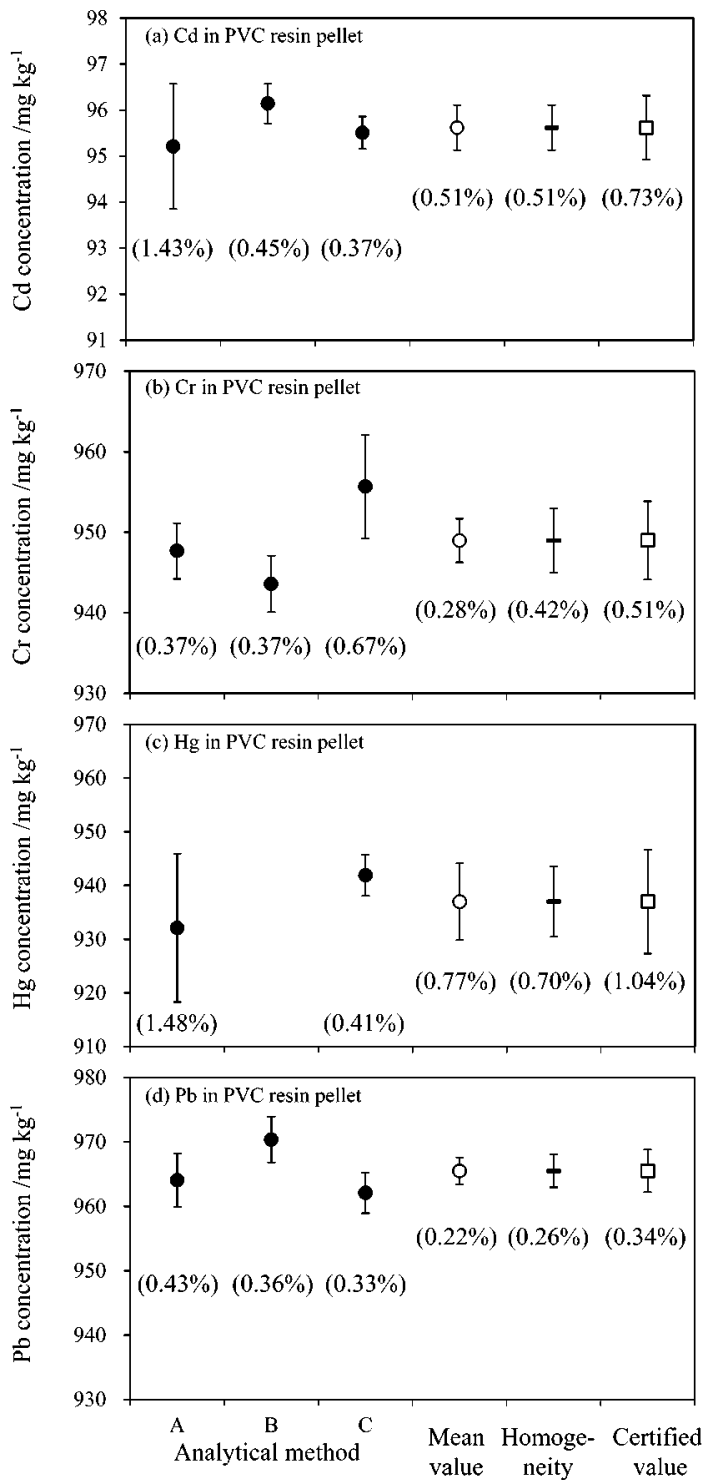

Fig. 1 Analytical results obtained for each analytical method ( mean value calculated from different analytical results $(\bigcirc)$, homogeneities (-) and certified values ( $\square$ ) of (a) Cd, (b) $\mathrm{Cr}$, (c) $\mathrm{Hg}$ and (d) $\mathrm{Pb}$ in the PVC resin pellet. The analytical methods are (A) isotope dilution ICPMS with the $\mathrm{HNO}_{3}-\mathrm{H}_{2} \mathrm{SO}_{4}$ microwave digestion procedure, (B) standard addition ICPOES with the $70 \% \mathrm{HNO}_{3}$ microwave digestion procedure and $(\mathrm{C})$ standard addition ICPOES with dry-ashing followed by the $\mathrm{HNO}_{3}-\mathrm{H}_{2} \mathrm{O}_{2}$ digestion procedure. The certified values were the mean values calculated from $2(\mathrm{Hg})$ or 3 analytical results. The values of the homogeneity for each element are indicated as being the same as those of the mean and the certified values. The bar indicated is the combined standard uncertainty $(k=1)$ estimated for each analytical method, the mean value and the certified value. The bar of the homogeneity is the standard deviation (SD) obtained by evaluating the homogeneity. The combined standard uncertainty of the certified value was calculated by the square root of the sum of the squares of the combined standard uncertainty of the mean value, the SD of the homogeneity and the standard uncertainty of the standard solution $(0.05 \%, k=1)$. The value in parentheses is the relative value $(\%)$.

were concerned to be precipitated with $\mathrm{SO}_{4}{ }^{2-}$ after microwave heating. Although precipitation may disturb accurate $\mathrm{Pb}$ determination by the calibration curve and the standard addition methods, IDMS achieves an accurate determination because the
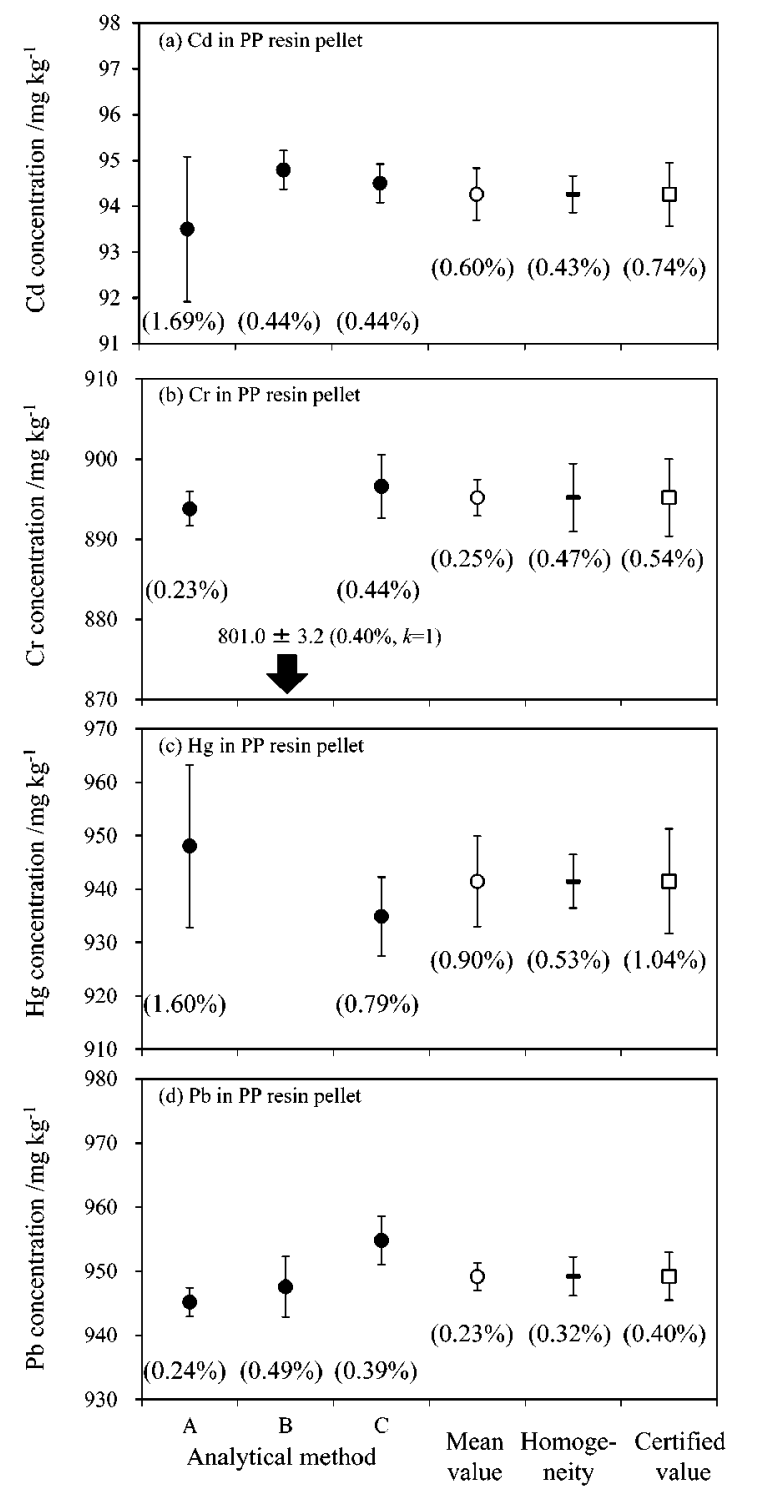

Fig. 2 Analytical results obtained for each analytical method $(\bullet)$, mean value calculated from different analytical results $(\bigcirc)$, homogeneities (-) and certified values ( $\square$ ) of (a) Cd, (b) $\mathrm{Cr}$, (c) $\mathrm{Hg}$ and (d) $\mathrm{Pb}$ in the $\mathrm{PP}$ resin pellet. The analytical methods are (A) isotope dilution ICPMS with the $\mathrm{HNO}_{3}-\mathrm{H}_{2} \mathrm{SO}_{4}$ microwave digestion procedure, (B) standard addition ICPOES with the $70 \% \mathrm{HNO}_{3}$ microwave digestion procedure and $(\mathrm{C})$ standard addition ICPOES with dry-ashing followed by the $\mathrm{HNO}_{3}-\mathrm{H}_{2} \mathrm{O}_{2}$ digestion procedure. The certified values were the mean values calculated from $2(\mathrm{Cr}$ and $\mathrm{Hg}$ ) or 3 analytical results. The values of the homogeneity for each element are indicated as being the same as those of the mean and the certified values. The bar indicated is the combined standard uncertainty $(k=1)$ estimated for each analytical method, the mean value and the certified value. The bar of the homogeneity is the standard deviation (SD) obtained by the homogeneity evaluation. The combined standard uncertainty of the certified value was calculated by the square root of the sum of the squares of the combined standard uncertainty of the mean value, the SD of the homogeneity and the standard uncertainty of the standard solution $(0.05 \%, k=1)$. The value in parentheses is the relative value $(\%)$.

final $\mathrm{Pb}$ isotope ratio obtained after achieving isotopic equilibrium during the sample digestion procedure, which has an effect on the determination of $\mathrm{Pb}$, does not change even if a few amounts of $\mathrm{Pb}$ are precipitated. Therefore, the mixed acid 
of $\mathrm{HNO}_{3}$ and $\mathrm{H}_{2} \mathrm{SO}_{4}$ was used for the microwave digestion procedure with respect to the IDMS. The analytical results obtained by the IDMS for the PVC and PP resin pellets are shown in Figs. 1 and 2, respectively. The maximum concentrations evaluated for $\mathrm{Cd}, \mathrm{Cr}, \mathrm{Hg}$ and $\mathrm{Pb}$ in a blank solution of the mixed acid of $\mathrm{HNO}_{3}$ and $\mathrm{H}_{2} \mathrm{SO}_{4}$ were enough low with respect to the analytical results $(0.1,1.2,0.1$ and $0.002 \mathrm{mg} \mathrm{kg}^{-1}$ for the PVC and the PP resin pellets). The alternative acid combinations were examined to avoid any inaccuracy in the $\mathrm{Pb}$ determination by the calibration curve and the standard addition methods. As can be found in Table 1, $70 \% \mathrm{HNO}_{3}$ can be used as an alternative acid for both the PVC and the PP resin pellets. In the case of the PVC resin pellet, complete digestion could be achieved by $70 \% \mathrm{HNO}_{3}$ if number of vessels of the microwave digestion system reduced or the microwave heating program was repeated for 2 or 3 times. An aquaregia and a reverse-aquaregia could also achieve complete digestion of the PVC resin pellet, if the microwave heating program was repeated for 2 or 3 times. From these results, $70 \%$ $\mathrm{HNO}_{3}$ was chosen for the microwave digestion procedure, even though the number of vessels should be reduced from 10 to 5 to achieve complete digestion of the PVC resin pellet in a single microwave heating program. In order to establish a second analytical method beyond the IDMS, we chose the standard addition method using ICPOES. Several analytical methods consisting of different sample pretreatment and measurement procedures are recommended and required for CRM development, because the certified value determined by several analytical methods are more reliable than that determined by a single analytical method. From the theoretical point of view, the IDMS and the standard addition method are different measurement procedures because they measure the isotope ratio and the signal intensity of elements, respectively. Moreover, since ICPMS and ICPOES detect ions and emission of elements, respectively; it can be considered that they are different measurement procedures. Therefore, we decided to use ICPOES rather than ICPMS for the standard addition method in this study. Since $70 \% \mathrm{HNO}_{3}$ for the microwave digestion procedure was diluted due to the addition of mixed standard solutions for the standard addition method, the amount of the PVC resin pellet was also reduced to 2 pellets $(c a .0 .06 \mathrm{~g})$ from 3 pellets (ca. $0.09-0.1 \mathrm{~g}$ ) to achieve complete digestion in a single microwave heating program. The analytical results obtained by the standard addition ICPOES with the $70 \% \mathrm{HNO}_{3}$ microwave digestion procedure for the PVC and the PP resin pellets are shown in Figs. 1 and 2, respectively. The maximum concentrations estimated for $\mathrm{Cd}, \mathrm{Cr}, \mathrm{Hg}$ and $\mathrm{Pb}$ in a blank solution were sufficiently low with respect to the analytical results $\left(0.05,0.5,1.6\right.$ and $1.3 \mathrm{mg} \mathrm{kg}^{-1}$ for the PVC and the PP resin pellets).

\section{Examination on dry-ashing followed by the $\mathrm{HNO}_{3}-\mathrm{H}_{2} \mathrm{O}_{2}$ digestion procedure}

Dry-ashing followed by acid digestion procedure was applied as a different sample pretreatment procedure compared to that of the microwave acid digestion procedure. Unfortunately, this sample pretreatment procedure does not fit to $\mathrm{Hg}$ analysis because it is not a closed system, which can not keep volatile elements, such as $\mathrm{Hg}$. About $0.5 \mathrm{~g}$ of the PVC or the PP resin pellets was weighed accurately and put them into a quartz beaker without any reagents. The beaker was put inside an electric furnace for dry-ashing. Although $\mathrm{H}_{2} \mathrm{SO}_{4}$ is used generally for dry-ashing, we do not use it to avoid the risk of $\mathrm{Pb}$ precipitation. A lower temperature can be considered to avoid the loss of elements. In our previous work, ${ }^{14}$ we chose a dry-ashing temperature of $350^{\circ} \mathrm{C}$ which was hold for $6 \mathrm{~h}$ for dry-ashing on ABS (acrylonitrile-butadiene-styrene) resin pellets. After the dry-ashing procedure, the obtained ash (residue) of the ABS resin pellets was dissolved successfully by a hot-plate heating procedure with $\mathrm{HNO}_{3}$ and $\mathrm{H}_{2} \mathrm{O}_{2}$. Figures 3(a)-3(d) show the obtained residues after the dry-ashing procedure for the PVC and the PP resin pellets. The ash obtained for the PVC resin pellet (Fig. 3(a)) was similar to that of the ABS resin pellet under a dry-ashing condition of $350^{\circ} \mathrm{C}$ for $6 \mathrm{~h}$. We examined dry-ashing at $300^{\circ} \mathrm{C}$ for 1,3 and $6 \mathrm{~h}$ concerning the PVC resin pellet; however, the ashes obtained could not be dissolved by the hot-plate heating procedure. The dry-ashing procedures at $350^{\circ} \mathrm{C}$ for 1,3 and $6 \mathrm{~h}$ were also examined on the PVC resin pellet. Although the obtained ashes could be dissolved by the hot-plate heating procedure, the dissolution of ash obtained for $6 \mathrm{~h}$ was easier than those of the others. The ashing temperature at $400^{\circ} \mathrm{C}$ resulted in a yellow residue of the PVC resin pellet, as shown in Fig. 3(b) which was concerned a loss of elements, even though dissolution of the residue was easy. Therefore, the dry-ashing condition of $350^{\circ} \mathrm{C}$ for $6 \mathrm{~h}$ was adopted for the PVC resin pellet. In the case of the $\mathrm{PP}$ resin pellet, different residues from those of the PVC resin pellet were obtained, as shown in Figs. 3(c) and 3(d). Although the dry-ashing temperatures at 250,300 and $325^{\circ} \mathrm{C}$ as well as the ashing times of 1, 3 and $6 \mathrm{~h}$ were examined for the PP resin pellet, a similar residue like coal tar as shown in Fig. 3(c) was obtained. The residue could be dissolved by the hot-plate heating procedure, but it was very difficult. A similar residue to that of Fig. 3(c) was also observed when the dry-ashing procedures at $350^{\circ} \mathrm{C}$ for 1 and $3 \mathrm{~h}$ were carried out. However, if the ashing time at $350^{\circ} \mathrm{C}$ was increased to $6 \mathrm{~h}$, a different residue, as shown in Fig. 3(d), was obtained that concerned the loss of elements, even though the residue could be dissolved easily. Because the residue shown in Fig. 3(c) was absolutely difficult to decompose by the hot-plate heating procedure, the dry-ashing condition at $350^{\circ} \mathrm{C}$ for $6 \mathrm{~h}$ was chosen on the PP resin pellet. The analytical results obtained by the standard addition ICPOES with dry-ashing followed by the $\mathrm{HNO}_{3}-\mathrm{H}_{2} \mathrm{O}_{2}$ digestion procedure for the PVC and the PP resin pellets are shown in Figs. 1 and 2, respectively. The maximum concentrations estimated for $\mathrm{Cd}, \mathrm{Cr}$ and $\mathrm{Pb}$ in a blank solution were enough low with respect to the analytical results $(0.1,0.5$ and $1.1 \mathrm{mg} \mathrm{kg}^{-1}$ for the PVC and the PP resin pellets).

\section{Evaluation of the homogeneity of elements}

The homogeneity of elements in both the PVC and the PP resin pellets was evaluated. The relative standard deviation (RSD, \%) obtained for analytical results of 28 samples from 14 bottles (2 samples from each bottle) was evaluated as the homogeneity of elements in both the PVC and the PP resin pellets. A calibration curve method using ICPMS as well as the microwave digestion procedure with $70 \% \mathrm{HNO}_{3}$ was used to evaluate the homogeneity. About $0.1 \mathrm{~g}$ of the PVC and the PP resin pellets was used for the microwave digestion procedure. The results are indicated in Figs. 1 and 2. Relative values ranging from 0.3 to $0.7 \%$ were obtained as the homogeneity of elements in both plastic pellets. It was concluded that the homogeneity obtained was sufficiently small for the development of the CRMs and the values obtained were similar to those of our previous work. ${ }^{14}$

\section{Comparison of analytical results from different analytical methods}

Figures 1 and 2 show the analytical results obtained by different analytical methods established in this study. The mean 
(a)

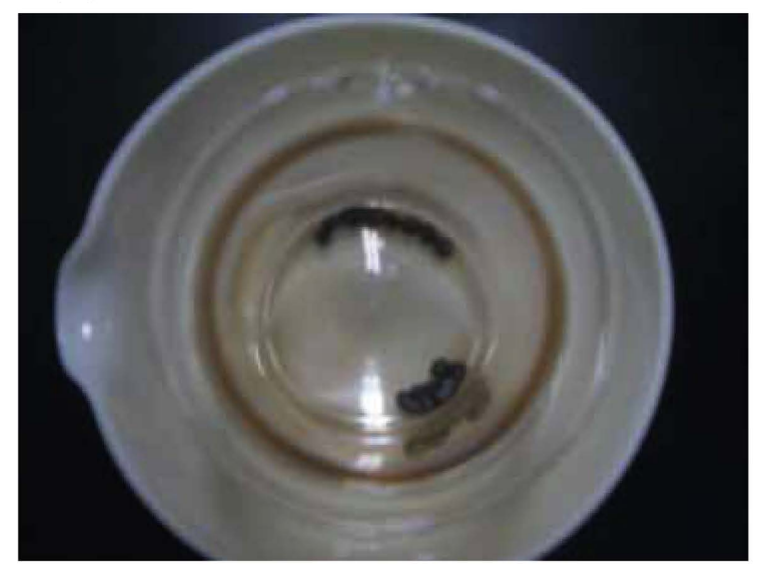

(c)

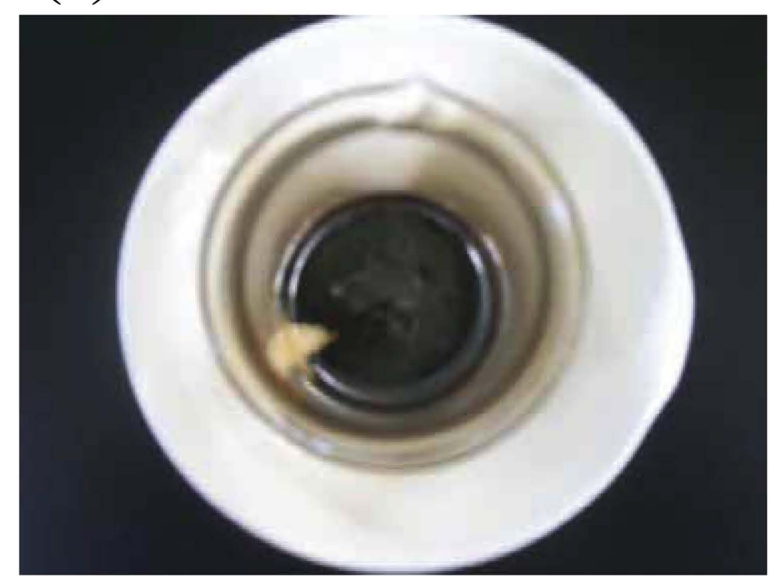

(b)

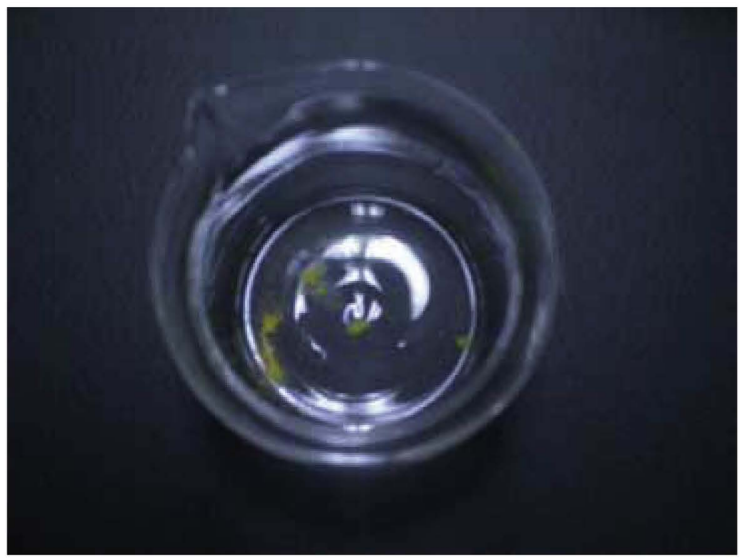

(d)

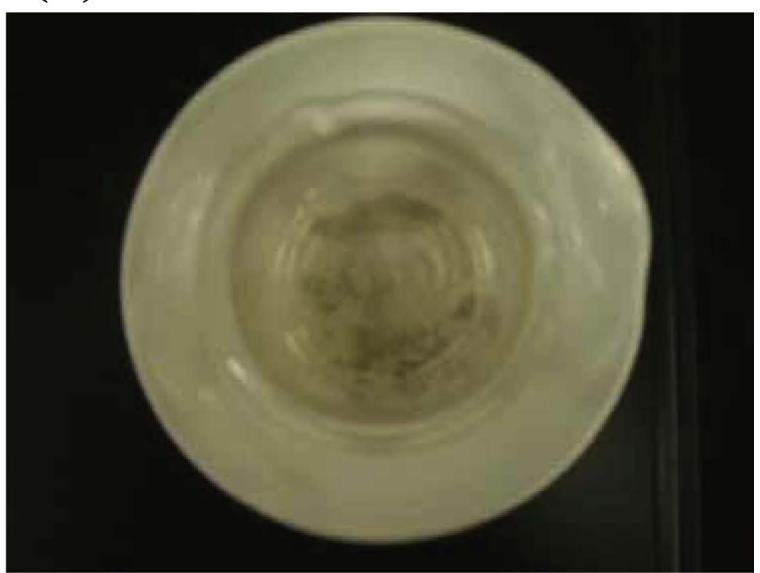

Fig. 3 Residues obtained after the dry-ashing procedure at different temperatures for $6 \mathrm{~h}$ : (a) at $350^{\circ} \mathrm{C}$ and (b) at $400^{\circ} \mathrm{C}$ for the PVC resin pellet, (c) at $325^{\circ} \mathrm{C}$ and (d) at $350^{\circ} \mathrm{C}$ for the PP resin pellet.

values calculated from different analytical results, the results of homogeneity as well as the certified values are also indicated. The combined standard uncertainties for each analytical method, the mean value as well as the certified value were estimated in accordance with references ${ }^{4,14,19}$ as well as GUM (Guide to the expression of Uncertainty in Measurement). ${ }^{20}$ Because the analytical results obtained agreed well within their combined standard uncertainties and the combined standard uncertainties were also at a similar level to each other, the mean value was adopted to determine the certified value. The analytical result of $\mathrm{Cr}$ for the $\mathrm{PP}$ resin pellet obtained by the dry-ashing procedure $\left(350^{\circ} \mathrm{C}\right.$ for $\left.6 \mathrm{~h}\right)$ was excluded from the calculation because the loss of $\mathrm{Cr}$ was considered. If a dry-ashing temperature of $300^{\circ} \mathrm{C}$ is adopted, the loss of $\mathrm{Cr}$ might be prevented. Even though the dry-ashing procedure $\left(350^{\circ} \mathrm{C}\right.$ for $\left.6 \mathrm{~h}\right)$ lost $\mathrm{Cr}$ from the PP resin pellet, it could keep $\mathrm{Cd}$ and $\mathrm{Pb}$ quantitatively. The analytical results obtained by the standard addition ICPOES with dry-ashing followed by the $\mathrm{HNO}_{3}-\mathrm{H}_{2} \mathrm{O}_{2}$ digestion procedure could be used for the determination of $\mathrm{Cd}, \mathrm{Cr}$ and $\mathrm{Pb}$ in the $\mathrm{PVC}$ resin pellet as well as $\mathrm{Cd}$ and $\mathrm{Pb}$ in the $\mathrm{PP}$ resin pellet, even though the sample pretreatment procedure was an open system, complicated and time consuming. ${ }^{14}$ The combined standard uncertainty estimated for each element $(0.4-0.5 \%)$ originated from the uncertainty estimated from the regression curve obtained by the standard addition method including the sample pretreatment procedure. The analytical results obtained by the isotope dilution ICPMS with the $\mathrm{HNO}_{3}-\mathrm{H}_{2} \mathrm{SO}_{4}$ microwave digestion procedure are reliable because the analytical method is accepted as a primary method of measurement; however, the method is not under widespread use because enriched isotopes of elements are necessary and a single element measurement (non multi-element analysis) is recommended to achieve a high precision of the measurement which leads to a lower sample throughput. The combined standard uncertainties estimated for $\mathrm{Cd}$ and $\mathrm{Hg}(1.4-1.7 \%)$ were relatively larger than those of $\mathrm{Cr}$ and $\mathrm{Pb}(0.2-0.4 \%)$, which were attributed to the large uncertainties of the isotope ratios estimated from the uncertainties of the isotopic abundances of $\mathrm{Cd}$ and $\mathrm{Hg}$ listed in IUPAC..$^{14,18}$ The standard addition ICPOES with the $70 \% \mathrm{HNO}_{3}$ microwave digestion procedure was also a useful analytical method for $\mathrm{Cd}, \mathrm{Cr}, \mathrm{Hg}$ and $\mathrm{Pb}$ in both the $\mathrm{PVC}$ and the $\mathrm{PP}$ resin pellets, because the analytical results obtained agreed with those of other analytical methods within their combined standard uncertainties estimated. The combined standard uncertainty estimated for each element $(0.4-0.8 \%)$ originated from the same source for the standard addition method including the sample pretreatment procedure. According to the purpose for the development of CRMs, ICPOES was chosen in this study; 
Table 2 Certified values for both the PVC and the PP resin pellet CRMs

\begin{tabular}{ccc}
\hline & $\begin{array}{c}\text { PVC resin pellet CRM } \\
\text { (NMIJ CRM 8123-a) }\end{array}$ & $\begin{array}{c}\text { PP resin pellet CRM } \\
\text { (NMIJ CRM 8133-a) }\end{array}$ \\
\hline $\mathrm{Cd}$ & $95.62 \pm 1.39$ & $94.26 \pm 1.39$ \\
$\mathrm{Cr}$ & $949.0 \pm 9.7$ & $895.2 \pm 9.6$ \\
$\mathrm{Hg}$ & $937.0 \pm 19.4$ & $941.5 \pm 19.6$ \\
$\mathrm{~Pb}$ & $965.5 \pm 6.6$ & $949.2 \pm 7.5$ \\
\hline
\end{tabular}

The numeric value after the symbol \pm of each certified value indicates an expanded uncertainty, determined with the coverage factor $k=2$; it defines an interval estimated to have a level of confidence of approximately $95 \%$.

however, ICPMS can be applied instead of ICPOES. The combined standard uncertainty of the certified value was calculated from the combined standard uncertainties of the mean value $(0.3-0.9 \%)$, the standard deviation of the element obtained by the evaluation of homogeneity $(0.3-0.7 \%)$ and the standard uncertainty of the standard solution $(0.05 \%, k=1)$. As can be seen in Figs. 1 and 2, the uncertainties between the mean value and the homogeneity had similar level of amount and it was concluded that they were the main source of the final uncertainty of the certified value. Table 2 gives the certified values as well as expanded uncertainties estimated $(k=2)$ for $\mathrm{Cd}, \mathrm{Cr}, \mathrm{Hg}$ and $\mathrm{Pb}$ in both the PVC and the PP resin pellets as NMIJ CRM 8123-a and 8133-a, respectively. The expanded uncertainties estimated for $\mathrm{Hg}$ were relatively larger than those of other elements, because they were calculated from only two analytical methods including the IDMS which resulted in the large combined standard uncertainty on $\mathrm{Hg}$, as can be seen in Figs. 1 and 2. As mentioned above, since the analytical results obtained were consistent with each other within their similar combined standard uncertainties and the certified value was determined from those obtained by different analytical methods, including the IDMS which was accepted as a primary method of measurement, it was evaluated that the analytical methods established in this study were reliable with high accuracy and the CRMs developed have international consistency.

\section{Evaluation of the stability of elements}

Figures 4 and 5 show the results concerning the stability of elements for both the PVC and the PP resin pellets, respectively. The consistency between the certified value and the analytical results was judged by the following:

$$
\left|C_{\text {stab.i }}-C_{\mathrm{CRM}}\right|<\sqrt{\left(\left(2 u_{\text {stab.i }}\right)^{2}+U_{\mathrm{CRM}}^{2}\right)} .
$$

$C_{\text {stab.i }}$ and $C_{\mathrm{CRM}}$ are the analytical results for the stability of elements and the certified values $\left(\mathrm{mg} \mathrm{kg}^{-1}\right)$, respectively. The $u_{\text {stab.i }}$ is the standard uncertainty of the analytical results $\left(\mathrm{mg} \mathrm{kg}^{-1}\right)$ for the stability of elements and $U_{\mathrm{CRM}}$ is the expanded uncertainty of the certified value $\left(\mathrm{mg} \mathrm{kg}^{-1}\right)$. The values for both $2 u_{\text {stab.i }}$ and $U_{\text {CRM }}$ should be similar, if the judgement is conducted. Since the IDMS was a reliable analytical method, it was applied to evaluating the stability of elements after certification even though it resulted in larger combined standard uncertainties for both $\mathrm{Cd}$ and $\mathrm{Hg}$, as can be seen in Figs. 4 and 5. According to the judgement, it was evaluated that the analytical results obtained before and after the certification were consistent with the certified values. From these results, it was concluded that both the PVC and the PP resin pellet CRMs were stable for a monitoring period of more than 5 years. Consequently, the

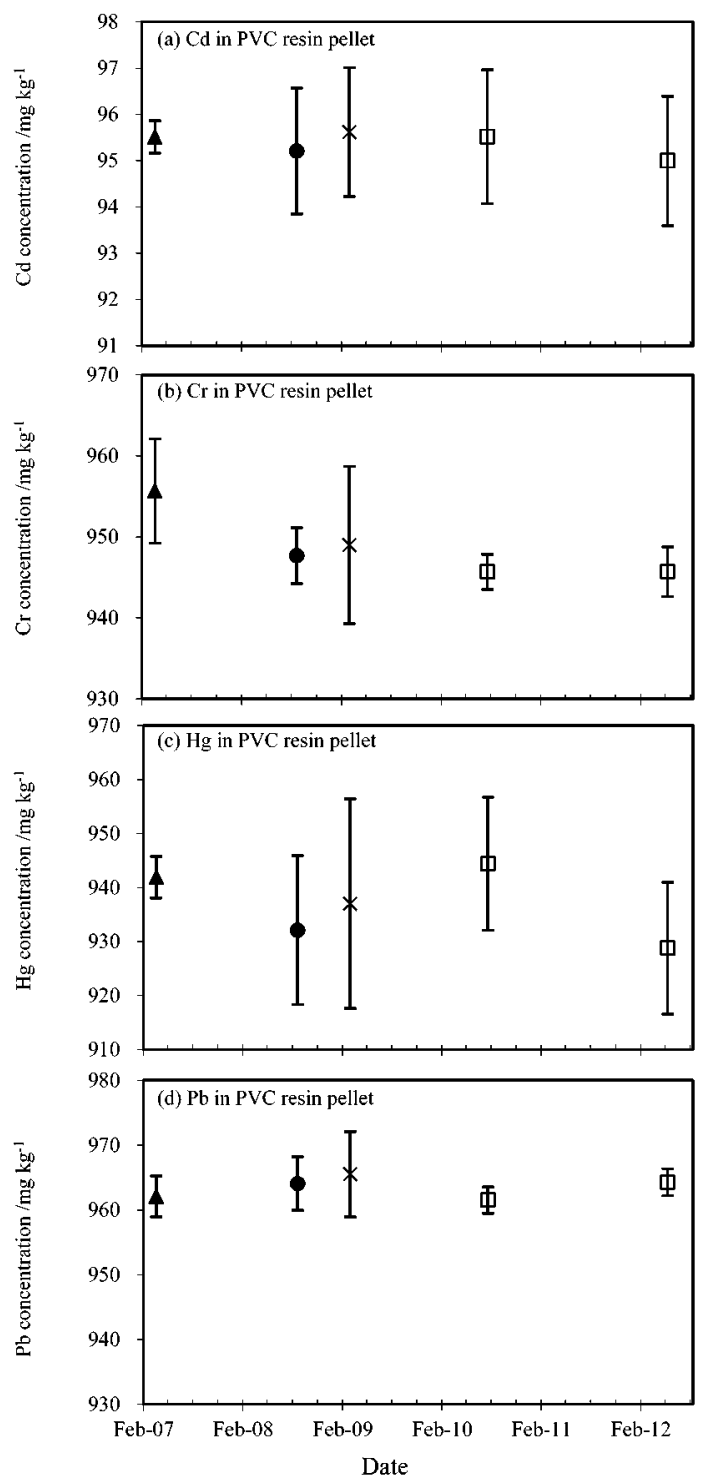

Fig. 4 Results of stability for (a) $\mathrm{Cd}$, (b) $\mathrm{Cr}$, (c) $\mathrm{Hg}$ and (d) $\mathrm{Pb}$ in the PVC resin pellet; analytical result obtained by standard addition ICPOES with the $70 \% \mathrm{HNO}_{3}$ microwave digestion procedure before certification $(\mathbf{\Lambda})$, analytical result obtained by isotope dilution ICPMS with the $\mathrm{HNO}_{3}-\mathrm{H}_{2} \mathrm{SO}_{4}$ microwave digestion procedure before certification $(\bullet)$, certified value certified on March $2009(\times)$, analytical results obtained by isotope dilution ICPMS with the $\mathrm{HNO}_{3}-\mathrm{H}_{2} \mathrm{SO}_{4}$ microwave digestion procedure after the certification $(\square)$. The bars indicated are the combined standard uncertainty $(k=1)$ and the expanded uncertainty $(k=2)$ estimated for each analytical result and the certified value, respectively.

CRMs are expected to be stable for a long time if they are stored in an appropriate space in accordance with the certification. ${ }^{21}$

\section{Conclusions}

The PVC and the PP resin pellet CRMs of NMIJ CRM 8123-a and 8133-a, respectively, with respect to the RoHS directive were developed in this study. Both the sample pretreatment and the measurement procedures for the determination of $\mathrm{Cd}, \mathrm{Cr}, \mathrm{Hg}$ and $\mathrm{Pb}$ in the PVC and the PP resin pellets were examined and these analytical methods such as the isotope dilution ICPMS 

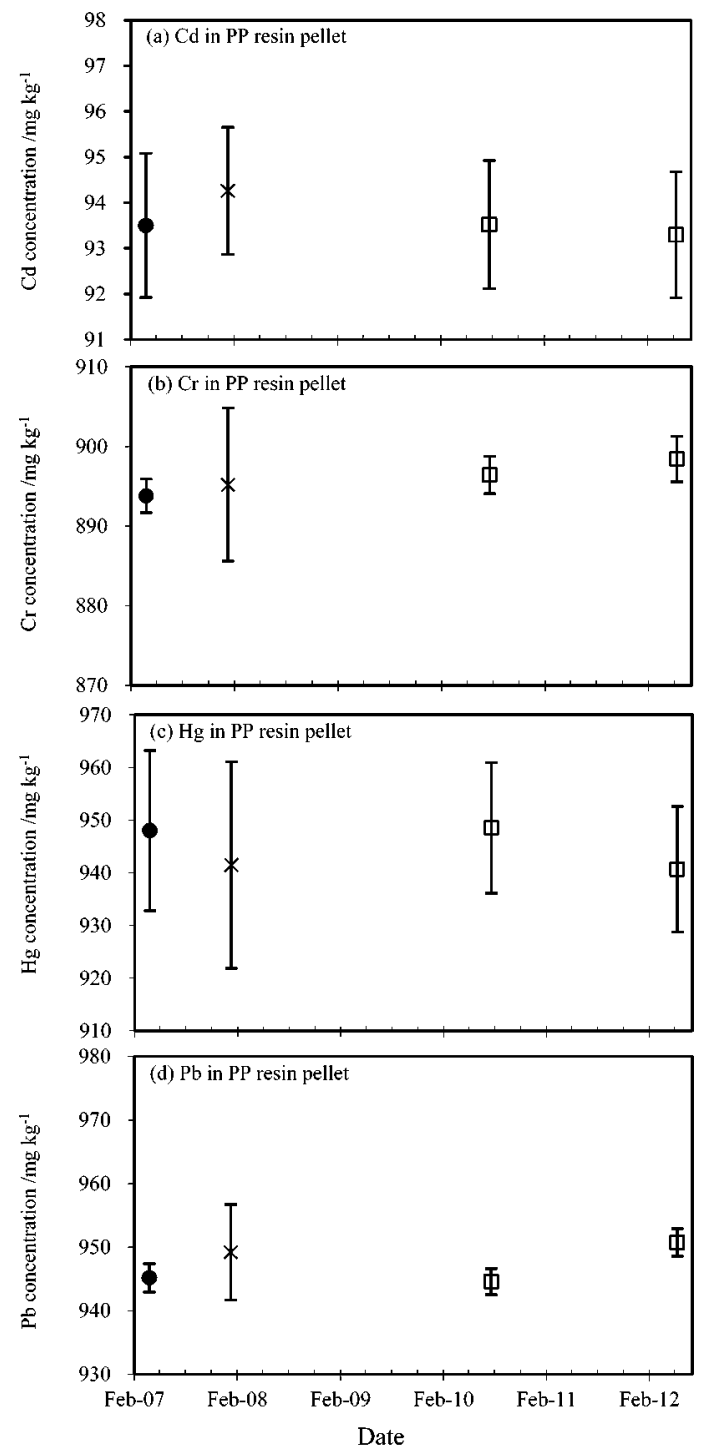

Fig. 5 Results of stability for (a) $\mathrm{Cd}$, (b) $\mathrm{Cr}$, (c) $\mathrm{Hg}$ and (d) $\mathrm{Pb}$ in the PP resin pellet; analytical result obtained by isotope dilution ICPMS with the $\mathrm{HNO}_{3}-\mathrm{H}_{2} \mathrm{SO}_{4}$ microwave digestion procedure before certification (๑), certified value certified on January $2008(\times)$, analytical results obtained by isotope dilution ICPMS with the $\mathrm{HNO}_{3^{-}}$ $\mathrm{H}_{2} \mathrm{SO}_{4}$ microwave digestion procedure after the certification $(\square)$. The bars indicated are the combined standard uncertainty $(k=1)$ and the expanded uncertainty $(k=2)$ estimated for each analytical result and the certified value, respectively.

with $\mathrm{HNO}_{3}-\mathrm{H}_{2} \mathrm{SO}_{4}$ microwave digestion, the standard addition ICPOES with $70 \% \mathrm{HNO}_{3}$ microwave digestion and the standard addition ICPOES with dry-ashing followed by $\mathrm{HNO}_{3}-\mathrm{H}_{2} \mathrm{O}_{2}$ digestion procedures were developed. Since the analytical results obtained by different analytical methods, including IDMS which was accepted as a primary method of measurement, showed good agreement within their uncertainties estimated, it was concluded that the analytical methods established in this study were reliable with high accuracy and the CRMs developed have international consistency. The homogeneity and the stability of $\mathrm{Cd}, \mathrm{Cr}, \mathrm{Hg}$ and $\mathrm{Pb}$ in these plastic pellet CRMs were also evaluated, and the results revealed sufficient homogeneity of $0.3-0.7 \%$ and stability for more than 5 years, which satisfied the requirement of CRM. The uncertainties estimated for both the analytical methods and the homogeneity were the main sources of the final uncertainty of the certified value and the final uncertainty was also sufficiently small with respect to the requirement of the CRM. From these results, it is considered that these CRMs are useful CRM for the determination of $\mathrm{Cd}$, $\mathrm{Cr}, \mathrm{Hg}$ and $\mathrm{Pb}$ in plastics with respect to the RoHS directive.

\section{References}

1. Directive 2002/95/EC of the European parliament and of the council of 27 January 2003, on the restriction of the use of certain hazardous substances in electrical and electronic equipment, Official Journal of the European Union, 13. 2, 2003.

2. Directive 2011/65/EC of the European parliament and of the council of 8 June 2011, on the restriction of the use of certain hazardous substances in electrical and electronic equipment (recast), Official Journal of the European Union, 1. 7, 2011.

3. W. V. Borm, A. Lambery, and P. Quevauviller, Fresenius J. Anal. Chem., 1999, 365, 361.

4. J. Vogl, D. Liesegang, M. Ostermann, J. Diemer, M. Berglund, C. R. Quetel, P. D. P. Taylor, and K. G. Heumann, Accredit. Qual. Assur., 2000, 5, 314.

5. P. Quevauviller, Trend Anal. Chem., 2001, 20, 446.

6. A Lambery, W. V. Borm, and P. Quevauviller, Fresenius J. Anal. Chem., 2001, 370, 811.

7. K. Eliola and P. Peramaki, Analyst, 2003, 128, 194.

8. C. Mans, S. Hanning, C. Simons, A. Wegner, A. Janßen, and M. Kreyenschmidt, Spectrochim. Acta, Part B, 2007, 62,116

9. IEC 62321, International Standard: Electrotechnical products-Determination of levels of six regulated substances (lead, mercury, cadmium, hexavalent chromium, polybrominated biphenyls, polybrominated diphenyl ethers), Edition 1.0, 2008.

10. K. Nakano, T. Nakamura, I. Nakai, A. Kawase, M. Imai, M. Hasegawa, Y. Ishibashi, I. Inamoto, K. Sudou, M. Kozaki, A. Turuta, H. Honma, A. Ono, K. Kakita, and M. Sakata, Bunseki Kagaku, 2006, 55, 501.

11. K. Nakano, T. Nakamura, I. Nakai, A. Kawase, M. Imai, M. Hasegawa, Y. Ishibashi, I. Inamoto, K. Sudou, M. Kozaki, A. Turuta, A. Ono, K. Kakita, and M. Sakata, Bunseki Kagaku, 2006, 55, 799.

12. K. Nakano, T. Nakamura, I. Nakai, A. Kawase, M. Imai, M. Hasegawa, Y. Ishibashi, I. Inamoto, K. Sudou, M. Kozaki, A. Tsuruta, A. Ono, K. Kakita, and M. Sakata, Anal. Sci., 2006, 22, 1265.

13. K. Nakano, T. Nakamura, I. Nakai, A. Kawase, M. Imai, M. Hasegawa, Y. Ishibashi, I. Inamoto, K. Sudou, M. Kozaki, A. Turuta, A. Bando, A. Ono, K. Kakita, K. Takimoto, and M. Sakata, Bunseki Kagaku, 2007, 56, 363.

14. M. Ohata, M. Kurahashi, and A. Hioki, BUNSEKI KAGAKU, 2008, 57, 417.

15. M. Kurahashi, T. Kidokoro, M. Ohata, S. Matsuyama, S. Kinugasa, and A. Hioki, Adv. X-ray Chem. Anal., Jpn., 2009, 40, 203.

16. M. Ohata, T. Kidokoro, M. Kurahashi, and A. Hioki, Bunseki Kagaku, 2010, 59, 903.

17. M. Ohata, T. Kidokoro, and A. Hioki, Anal. Sci., 2012, 28, 1105.

18. J. R. de Laeter, J. K. Böhlke, P. De Bievre, H. Hidaka, H. S. Peiser, K. J. R. Rosman, and P. D. P. Taylor, Pure Appl. Chem., 2003, 75, 683.

19. R. L. Watters Jr., K. R. Eberhardt, E. S. Beary, and J. D. 
Fassett, Metrologia, 1997, 34, 87.

20. BIPM, IEC, IFCC, ISO, IUPAC, OIML, "Guide to the expression of uncertainty measurement", 1993, Internal
Organization for Standardization, Geneva, Switzerland. 21. http://www.nmij.jp/service/C/crm/ 